\title{
С.Г. Арбузов
}

\section{ТЕНАЕНЦИИ РАЗВИТИЯ УКРАИНЫ В ПЕРИОА 2007-2015 rr.}

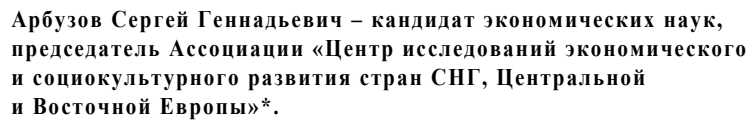

После распада СССР и традиционных хозяйственных связей украинская экономика вступила в полосу затяжного кризиса. К 1999 г. ВВП Украины снизился до 40\%-ного уровня показателей 1991 г., и в дальнейшем серьезных успехов усилия властей по подъему экономики не принесли. Так, в 2011 г. журнал Forbes поместил Украину на четвертое место после Гвинеи в рейтинге десяти худших экономик мира [2]. Перманентное кризисное положение дел в экономике страны неизбежно сказалось и на возможностях социального развития, причем негативное влияние усугублялось недостаточно эффективным государственным управлением, в частности в налоговой сфере, призванной обеспечить трансформацию результатов экономической деятельности в возможности защиты государством социальных потребностей и запросов общества, по данным Всемирного банка, Украина в 2014 г. занимала 164-е место в рейтинге налоговых систем мира [3, с. 165-166].

Одним из факторов, негативно влиявших все эти годы на развитие Украины, является низкий уровень политической стабильности. Достаточно отметить, что за период после распада СССР в Украине сменилось пять президентов, девять премьер-министров и девять председателей Верховной рады. При этом только в 2007 г. сложилась ситуация, когда и президент (на тот момент Виктор Ющенко), и премьер-министр (на конец 2007 г. - Юлия Тимошенко) входили в одну партию или коалицию. Учитывая это обстоятельство,

* С 28 января по 27 февраля 2014 г. - и.о. премьер-министра Украины; с декабря 2010 г. по декабрь 2012 г. - председатель Национального банка Украины. 
а также вступившие в силу незадолго до этого изменения в Конституции Украины, передавшие часть полномочий президента Верховной раде, можно сделать вывод, что с 2007 г. в государственном управлении Украины завершился переход от системы, ориентированной на одного человека (президента) к президентско-парламентской системе, в большей степени ориентированной на политические силы, формирующие правящую коалицию и представляющие значительную часть общества. В силу указанного обстоятельства эти силы вынуждены были разрабатывать и согласовывать государственную политику на более длительную перспективу и на основе более системного подхода, чем при чисто президентском правлении. Этим обусловлен особый интерес к данному периоду развития Украины в настоящем исследовании, посвященном эффективности государственной политики по обеспечению экономической безопасности.

Помимо низкого уровня политической стабильности можно выделить три группы причин, которые привели к кризисному состоянию украинской социально-экономической системы:

$-\kappa$ первой группе относятся причины, унаследованные от СССР. Это и избыточное огосударствление и монополизация экономики, отсутствие конкуренции между производителями и, соответственно, низкая конкурентоспособность выпускаемой продукции, сосредоточение на экспорте ресурсов, затратность экономики, высокие энергоемкость и электроемкость национальной экономики, антидемократический характер управления государственной собственностью и чрезмерная централизация при перераспределении национального дохода через государственный бюджет, милитаризация экономики, перераспределение значительной части созданного сельскими работниками национального дохода в пользу промышленности через механизм цен, низкий уровень производительности труда и многое другое;

- ко второй группе относятся причины, которые обусловлены неэффективными действиями власти в первые годы независимости страны, а именно:

- резкий разрыв хозяйственных связей со странами бывшего СССР, прежде всего с Россией, в результате чего Украина потеряла значительную долю традиционных рынков сбыта, и был остановлен ряд предприятий. При этом существующие хозяйственные связи не были эффективно модифицированы;

- отсутствие научно обоснованной стратегии трансформации командноадминистративной системы в развитую и совершенную экономическую систему, неопределенность модели такой трансформации (ставилась цель одновременного перехода к рыночной, социально ориентированной, смешанной экономике, а также к постиндустриальному обществу). Как следствие формирование неэффективного сочетания государственно-административного регулирования и стихии рынка. Другими словами, власти Украины 
хотели оставить все позитивное от экономической модели СССР и взять только позитивное от рыночной экономики, что привело к идеализации планов, малоуправляемой экономической ситуации и коррупции;

- неэффективность правовой системы (принятие неработающих, противоречивых или разрушительных по результатам законов, отсутствие механизма реализации многих из них);

- провалы денежно-кредитной политики (карбованцы не были оформлены как валютные ресурсы национальной банковской системы, а купоны не имели надежной защиты, что повлекло за собой их катастрофическое обесценивание, сделав средством опустошения национального рынка);

- шоковая либерализация цен, повлекшая обесценивание трудовых сбережений, что привело к минимизации нормы сбережений, резкому снижению покупательской способности большинства населения и его обнищанию;

- резкое увеличение доли импортных товаров на внутреннем рынке (доля которых достигла к 1999 г. $70 \%$ );

- проведение неэффективных конверсионных процессов (в 1991 г. доля военной продукции в общем объеме производства составляла почти $23 \%$, а в 1996 г. - примерно $3,4 \%)^{1}$;

- резкое увеличение налоговой нагрузки, а также изъятие в отдельные годы амортизационных отчислений в государственный бюджет;

- снижение доли принадлежащего государству национального дохода, приведшее в конечном итоге к снижению социальных расходов;

- проведение разгосударствления и приватизации, носящих теневой и криминальный характер, незаконное присвоение собственности представителями политической элиты (кланами) и бюрократизация аппарата исполнительной власти;

- постоянная смена правительств (до 2004 г. сменилось 11 правительств), большинство из которых, не выполнив принятых программ и планов, утвержденных бюджетов или отдельных статей, не понесла ответственности за это.

Отметим, что в начале периода рыночных преобразований страна находилась на довольно благоприятных позициях - более выгодных, чем большинство республик, включая Россию (до роста цен на энергию с 2003 г.). Однако кризис переходного периода в стране оказался одним из самых глубоких на всем постсоветском пространстве. Недостатки предыдущей экономики на начальном этапе развития независимого государства усилились вследствие некомпетентности власти, гипертрофированного стремления к личному

1. Здесь и далее (если не указано иначе) - официальные данные Госстата Украины, Национального банка Украины и Министерства финансов Украины. 
обогащению лиц, имевших доступ к национальным богатствам, криминализации экономической сферы и др.

После 1991 г. отмечались такие кризисные явления, как резкий спад производства; высокие темпы инфляции (в 1992 г. они составляли до $3000 \%$, в 1993 г. - более 10 000\%); массовая безработица, которая, по данным МВФ, охватывала около $35 \%$ трудоспособного населения; катастрофическое снижение жизненного уровня подавляющего большинства населения - по разным оценкам, от 5 до 10 раз; массовая миграция рабочей силы, в том числе высококвалифицированной, за границу; постоянное увеличение внешнего долга (если в 1991 г. он составил почти 400 млн долл., то в 1999 г. - более 12 млрд долл.; резкая поляризация общества; значительная депопуляция населения (с 1990 по 2003 г. численность населения сократилась на 4,5 млн человек); кризис недопроизводства и другие негативные явления.

Заметим, что, несмотря на некоторые присущие исключительно Украине ошибки, низкую эффективность ее государственного управления, подобные явления были достаточно типичными практически для всех государств бывших республик СССР: отсутствие четкой экономической политики (включая бюджетную, денежно-кредитную, налоговую и другие ее составляющие); некомпетентность органов государственной власти; неправильное применение ряда рыночных рычагов; негативное влияние международных финансово-кредитных организаций и т.д.

Третья группа причин является дистинктивной, порожденной специфическими особенностями трансформации сложившейся к концу 1990-х годов украинской экономической системы.

Формально динамика изменения структуры ВВП Украины в этот период соответствовала тенденциям наиболее развитых стран, осуществляющих переход к постиндустриальному типу общества: наиболее динамично развивающимся сектором экономики стал сектор услуг, доля которого в ВВП к концу 2000 -х годов достигла $60 \%$. Однако если в развитых странах главной отличительной чертой постиндустриального общества является очень высокая производительность труда, позволяющая при сохранении или даже росте промышленного производства высвободить из промышленности значительную часть работников, которые переходят в сферу высококачественных и инновационных услуг с высокой долей в ВВП, то в Украине основной причиной роста доли в ВВП сектора услуг стало резкое сокращение промышленного производства (при этом, в отличие от постиндустриального общества, где львиная доля приходится на инновационные услуги, в Украине основные отрасли сферы услуг - торговля, ремонт, гостиничный и ресторанный бизнес).

Значительная деиндустриализация, характерная для транзиционного кризиса на всем постсоветском пространстве, продолжилась в Украине 
и в 2000-х годах, что привело к снижению адаптивности, уровня сложности и как следствие - конкурентоспособности производимой продукции, а также экспортного потенциала страны в целом (при сохранении определенной конкурентоспособности значительной части крупных промышленных предприятий металлургической и оборонной промышленности - в основном на Востоке страны).

При этом также отмечалось сокращение доли сельского хозяйства (некоторый рост был отмечен только в 2013 г.) при очень высоком количестве занятых в данной сфере.

Негативные сдвиги обнаруживаются и во внутренней структуре промышленности - доля обрабатывающих производств снизилась на фоне растущих долей добывающей промышленности, производства и распределения электроэнергии, газа и воды. Следует также отметить сокращение доли металлургии и машиностроения. Единственным условно позитивным следствием такой деиндустриализации можно считать сокращение выброса $\mathrm{CO}_{2}$ и уменьшение другого негативного воздействия на экологию.

В 2000-2012 гг. заметные перемены произошли в топливноэнергетическом балансе Украины. В целом первичное потребление энергии за 12 лет снизилось на $8,3 \%$ - с 133,8 млн до 122,7 млн т н.э., что отражало как сокращение экономической активности в энергоемких отраслях и сектоpax, так и действие мер по повышению эффективности энергопотребления. Серьезно сократились импорт (с 77\% импорта всех энергоресурсов до 57) и потребление природного газа (с 47 всего первичного потребления до $35 \%$ ), при этом несколько выросло потребление собственных ресурсов - угля и атомной энергии (с 29 до 35\% и с 15 до 19\% соответственно).

Добыча всех энергоресурсов в стране за рассматриваемый период выросла на $12 \%$ - с 76,4 млн до 85,4 млн т н.э. При этом существенно повысилась роль возобновляемой энергетики (без учета ГЭС), чему способствовал едва ли не самый высокий «зеленый тариф» на электроэнергию в Европе (или даже в мире).

В стране так и не прошла нормализация отношений в газовом хозяйстве. При собственной добыче около 20 млрд м ${ }^{3}$ в год сбор платежей за газ отстает, и «Нафтогаз» находится в постоянном финансовом кризисе. По большому счету ни институциональные реформы, ни массированные вложения в ТЭК не были сделаны, несмотря на постоянные дебаты.

Короткий период экономического подъема 2006-2008 гг. был во многом обеспечен за счет увеличения товарного экспорта в Россию, а также денежных переводов, особенно из России. Мировой кризис 2008-2009 гг. резко остановил наметившийся было экономический подъем в стране. К политической нестабильности добавился связанный с внешнеполитическими конфлик- 
тами украинского руководства серьезный рост цен на газ, который усложнил проблемы бюджета и газоемких отраслей хозяйства.

При этом на украинском валютном рынке до определенного момента сохранялось равновесие между предложением и спросом на иностранную валюту за счет увеличения поступлений долларов от экспорта металлопродукции, изделий химической промышленности, зерна, таможенных пошлин и т.п. По приблизительным подсчетам, украинцы, работающие за границей, ежегодно переводили и перевозили в Украину иностранной валюты на сумму свыше 20 млрд долл. Значительное количество валюты одалживали у заграничных институций правительство, коммерческие банки, фирмы. Это давало возможность в известной степени покрывать потребности растущего импорта.

Однако с изменением конъюнктуры на мировом рынке значительно уменьшились инвалютные доходы от экспорта и таможни. Начался вывод иностранной валюты из банковской сферы, существенно уменьшились денежные переводы работников. В итоге на украинском валютном рынке нарушилось равновесие между предложением и спросом на доллар. Его курс стал неконтролированно расти. Возникла паника, которая еще больше усилила спрос на валюту.

Следует подчеркнуть, что Национальный банк осуществил превентивные мероприятия по стабилизации денежного обращения. В частности ограничил неконтролированную выдачу кредитов коммерческими банками, подняв для них норму резервирования и учетную ставку, ограничил эмиссию денег. Но эти меры оказались запаздывающими в условиях существенного увеличения денежной массы, роста импорта товаров и увеличения объема инвалютных потребительских кредитов - все это привело к росту спроса на иностранную валюту. Такой избыточный спрос на доллар Центральный банк был неспособен обеспечить даже при использовании всех резервов заграничной валюты.

Непрофессиональная деятельность Национального банка в период мирового финансового кризиса заключалась в необоснованном допущении свободного обращения в Украине иностранной валюты наряду с гривной, выдаче кредитов коммерческими банками в заграничной валюте. В результате этих действий в обращении оказалась неучтенная и никем не контролируемая валютная масса; было также спровоцировано появление избыточного количества импортных товаров. По выполненным автором оценкам, средний уровень долларизации экономики в этот период составлял около $50 \%$, что, по мнению специалистов, изучающих влияние долларизации на экономическую безопасность государства [1], превышает критическое (пороговое) значение, равное $45 \%$. Ситуацию на валютном рынке, кроме дефицита платежного баланса, ухудшало отсутствие финансовых инструментов хеджирования рисков для населения и компаний, что приводило к искусственному углублению дефицита платежного баланса. 


\section{РОССИЯ И МИР В ХХІ ВЕКЕ}

Таким образом, в период мирового экономического кризиса действия украинских властей по оздоровлению бюджетной сферы, а также последствия «газового» кризиса привели к ослаблению гривны. В период 2000-2008 гг. среднее значение обменного курса на Украине было на уровне 5,2 грн за доллар. Ряд событий, описанных выше, спровоцировал существенную девальвацию: в период 2009-2013 гг. среднее значение курса уже достигло 8 грн (в 2013 г. - 8,14 грн за доллар). В феврале-апреле 2014 г. произошло резкое падение курса гривны - до 11,5 грн за доллар, затем он стабилизировался, но в июле-августе вновь стал снижаться и к середине августа преодолел исторический рубеж в 13 грн за доллар, а Нацбанк Украины начал продажу долларов из резервов для стабилизации обстановки.

За период относительно спокойного развития экономики Украины в 2000-2007 гг. безработица увеличилась незначительно. В период кризиса 2008-2009 гг. этот показатель вырос до 8,8\%, после чего в 2010-2013 гг. стабилизировался, вновь показав негативную динамику в 2014-2015 гг.

Среднегодовые значения инфляции на Украине в 2000-х годах сильно колебались: от 0,8\% в 2002 г. до $25,2 \%$ в 2008 г. Всего же за 2002-2011 гг. цены в среднем выросли в 2,8 раза.

Одной их причин снижения устойчивости явились меры, проводимые правительством Ю.В. Тимошенко в рамках курса на рост благосостояния. Очевидно, что достичь увеличения народного потребления можно только за счет развития национального бизнеса, в первую очередь малого и среднего, роста производства товаров. В Украине же надлежащих условий для развития предпринимательства создано не было. Реальная экономика по существу не развивалась и не приносила значительных доходов. А производство мяса и молока ежегодно уменьшалось на 15-20\%. Лишь энергоемкие металлургическая и химическая промышленность наращивали производство экспортной продукции благодаря повышению на нее спроса на мировом рынке. Это и создало эйфорию экономического бума. В этих условиях правительство увеличивало ежегодные социальные выплаты населению на 35-40\% (зарплаты, пенсии, стипендии, пособия и т.п.). Для этого Национальный банк печатал и выпускал в обращение ежегодно свыше 60 млрд грн. Именно эти эмиссионные деньги в значительной мере пополняли доходы бюджета, из которого осуществлялись выплаты, что, кстати, было запрещено действующим законодательством.

В 2008 г. номинальные доходы украинцев выросли на 6,5 млрд грн, в том числе за счет выплат прежних долгов Сбербанком. Значительное увеличение денежной массы у граждан повлекло повышенный спрос на товары и стремительный рост инфляции.

Правительство хорошо понимало, что национальная экономика не способна производить необходимое количество товаров для покрытия избыточ126 
ных денежных выплат и избыточной оборотной денежной массы. Поэтому был сделан решительный шаг в сторону значительного увеличения закупки продукции за границей (импорт). Украина вышла на третье место в Европе по объемам покупки мобильных телефонов и на пятое - по объемам приобретения дорогих автомобилей. В итоге под воздействием двух основных факторов роста цены на закупаемый в России газ и провала курса на импортозамещение - торговый баланс изменился с позитивного на негативный. Если на 1 января 2005 г. доходы от экспорта превышали расходы импорта на 3,5 млрд долл. США, то на 1 января 2009 г. отрицательное сальдо торгового баланса составляло уже 15 млрд долл. При этом усилился дефицит иностранной валюты, обусловив тенденцию к обесцениванию гривны.

Необходимо также отметить, что массовая покупка товаров за границей способствовала уничтожению национальных производителей. Вследствие этого норма сбережений в Украине неуклонно падала на протяжении всего рассматриваемого периода. В 2004 г. объем сбережений достигал $31 \%$ ВВП; к 2008 г. сбережения сократились до $21 \%$; а по итогам 2013 г. упали, по официальным данным, до невероятного уровня в $6 \%$ ВВП.

Государственный бюджет Украины стабильно оставался дефицитным, причем размер дефицита увеличивался на протяжении всего периода. Отметим, что в структуре расходов бюджета Украины значительную долю традиционно занимали образование, социальная защита и социальное обеспечение (почти $2 / 3$ расходов консолидированного бюджета Украины), а затраты на экономическую деятельность оставались незначительными, что свидетельствует о недостаточности политики по развитию и оздоровлению экономики в период спада.

Многие специалисты называют наиболее стабильным период 20102012 гг. В сравнении с кризисными 2008-2009 гг. экономические показатели выглядели относительно неплохо: небольшое увеличение ВВП, приостановка роста инфляции, некоторое укрепление украинских позиций в международных рейтингах экономических свобод и легкости ведения бизнеса. В 2010 г. удалось получить два транша кредита от МВФ.

Уровень безработицы за этот период оставался существенно ниже кризисных показателей 2008-2009 гг. и был куда ниже показателей большинства стран Центральной и Южной Европы. По данным Международной организации труда, Украина вышла из экономического кризиса с безработицей среди людей 15-70 лет на уровне 8,8\%. По итогам 2012 г., данный показатель снизился до 7,5\%; наиболее существенно он сократился и по самой уязвимой категории - мужчины трудоспособного возраста (с 10,8 до 8,9\%). По итогам III квартала 2013 г., лишь 6,2\% населения в возрасте 15-70 лет не имели работы; среди людей трудоспособного возраста таковых было 6,7\%. 


\section{РОССИЯ И МИР В ХХІ ВЕКЕ}

По итогам 2009 г., номинальная средняя зарплата в Украине составляла 1906 грн, а на конец 2012 г. - уже 3026 грн. Росли соцстандарты: минимальная зарплата увеличилась с 869 грн (на январь 2010 г.) до 1147 грн (на январь 2013 г.), минимальная пенсия соответственно - с 695 грн до 894, увеличивались прожиточный минимум, стипендии, выплаты детских пособий, единовременная помощь при рождении ребенка была повышена с 15 тыс. до 25 тыс. грн.

Был принят новый Налоговый кодекс, введены каникулы для малого бизнеса, снижены ставки налогов.

Однако темпы преодоления последствий кризиса, усугубленных ошибками государственного управления в начале посткризисного периода и определенной политической нестабильностью, были недостаточными. Это привело к тому, что настигшая Украину во второй половине 2012 г. рецидивная волна мирового кризиса, существенно более слабая, чем основная (2008-2009), спровоцировала в 2013 г. острый экономический и социально-политический кризис в стране.

Начиная с 2012 г. мировая экономика росла более высокими темпами, чем украинская. В целом за 2010-2013 гг. доля Украины в мировом ВВП сократилась с 0,408 до $0,389 \%$. Из ключевых отраслей экономики к 2012 2013 гг. на предкризисный уровень вышло только сельское хозяйство. В то же время металлургия и машиностроение Украины к 2011 г. оказались на уровне лишь 85-90\% от 2008 г., а с 2012 г. и вовсе подверглись новому спаду. Строительные работы за 2009 г. сократились вдвое и с тех пор не смогли восстановить объемы. Серьезные проблемы для развития отдельных отраслей (металлургия, химия) создали относительно высокие цены на закупаемый в России природный газ.

Хроническое покрытие дефицита госфинансов на уровне 3-4\% ВВП позволяло правительству длительное время вести благоприятную социальную политику. Реальные доходы населения в 2010 г. выросли на $16,2 \%$, в 2011 - на 6,1, в 2012 г. - на 9,7\%. В начале 2013 г. этот показатель темпа роста $-7,6 \%$, замедлившийся к третьему кварталу до $1,9 \%$. Реальная заработная плата росла еще более высоким темпом - 14,4\% в 2012 г. и 8,2\% в 2013 г. В бюджете на 2014 г. был заложен рост прожиточного минимума и минимальной зарплаты на $6,8 \%$. Основное повышение намечалось на 1 октября 2014 г., за полгода до запланированных выборов президента.

Рост личных денежных переводов на Украину совпал с ростом нефтяных цен и экономическим подъемом в России, потребовавшим больше рабочей силы и увеличившим заработки украинских трудящихся в России. В 2013 г. только статистически видимые личные денежные переводы на Украину, по оценкам Всемирного банка, составили 9,3 млрд долл. По данным Нацбанка Украины, в 2013 г. более 7,3 млрд долл. (из них 36\% из России) было переведено на Украину только через банковские счета и международные платежные 
системы. Объем переводов, по неофициальным каналам, зафиксирован на уровне в 1,2 млрд долл. Экспорт рабочей силы с Украины в соседние страны позволял компенсировать торговый дефицит с ними.

Рост потребления на фоне рецессии приводил к высоким импортным закупкам и сокращению инвестиций. Валовое накопление основного капитала в 2013 г. сократилось, по данным Госстата, на 6,6\%. В целом объем капитальных инвестиций, освоенных предприятиями и организациями страны за счет всех источников финансирования, упал на $11,1 \%$. Чистый приток прямых иностранных инвестиций, согласно данным НБУ, в 2013 г. сократился вдвое: с 6,63 млрд до 3,35 млрд долл. США.

Значительная часть государственных инвестиций свернулась после проведения финальной части Чемпионата Европы по футболу. Капитальные расходы госбюджета в 2013 г. упали на $39,5 \%$, все ресурсы направлялись на текущие нужды.

Центральный банк проводил политику «дорогих» денег, обеспечивая стабильный обменный курс на уровне 7,9-8,2 грн / долл. Это вело к высоким ставкам по депозитам физических лиц в национальной валюте на уровне 17$19 \%$ годовых (данные индекса UIRD), что, помимо абсорбирующей роли, было важно для временного перераспределения банковских доходов в пользу населения, чьи доходы в этот период ощутимо снизились, а также для переориентации государственной долговой политики с МВФ на внутреннего инвестора. Очевидно, что цена кредитов для бизнеса значительно выросла ставки по долгосрочным кредитам находились в пределах $20-25 \%$, однако, по расчетам Минфина Украины с учетом появляющейся возможности выхода банковской системы на внешние рынки заимствования (а значит, и снижения стоимости привлечения средств), ситуация должна была сбалансироваться в течение двух-трех лет. Неконституционная смена власти в начале 2014 г. не позволила реализовать эти планы, так же как и впервые разработанную по инициативе автора Стратегию развития рынка финансовых услуг небанковского сектора, которая только за 2013 г. принесла значимые результаты: активы небанковского финансового сектора Украины увеличились на $24 \%$ и перешли уровень 127 млрд грн. В частности активы страховщиков выросли на $18 \%$; стоимость активов негосударственных пенсионных фондов возросла на 26; общие активы кредитных союзов увеличились на 30 ; кредитный портфель увеличился на 18 , а депозитный - на $5 \%$; объем задолженности по просроченным и невозвращенным кредитам, предоставленным членам кредитных союзов, уменьшился на $71 \%$.

Ключевой фактор, способствовавший тому, что рецессия оставалась умеренной - активная политика правительства по наращиванию внешнего и внутреннего долга. За девять лет внешний долг Украины вырос в 4,4 раза, в основном при президенте В. Ющенко: за 2005-2009 гг. - в 3,4 раза. Основной 
валютой внешних заимствований Украины является доллар США - около 3/4 объема долга. Около $40 \%$ госдолга имеет срок погашения до двух лет.

В начале 2014 г. валовый внешний долг Украины превысил 142 млрд долл. Около четверти этой суммы приходилось на государственный внешний долг - к июлю 2014 г. эта сумма выросла до 41 млрд долл. (включая 3 млрд долл. российских облигаций конца 2013 г.). Причем доля краткосрочного долга стабильно превышала $45 \%$, что держало финансовую систему страны в постоянном напряжении. Параллельно с ростом долга в последние годы происходило быстрое сокращение золотовалютных резервов страны - обеспеченность внешнего госдолга резервами упала со 100\% в январе 2011 г. до $40 \%$ в июле 2014 г. (объем резервов упал до 17 млрд долл.).

Несмотря на повышение налоговой нагрузки, в стране наблюдалась хроническая нехватка бюджетных доходов. По данным Министерства финансов, государственный бюджет в 2013 г. был недовыполнен на 3,4\%. Всего в казну поступило 339,2 млрд грн, что оказалось на 6,8 млрд грн меньше, чем в 2012 г. Объемы переплат (авансовой уплаты налогов) выросли на 4,1 млрд до 62 млрд грн. Сумма невозмещенного НДС на 1 января 2014 г. равнялась 14,9 млрд грн. При этом выросли специфические ставки акциза на спирт и ликероводочные изделия, винодельческую продукцию, коньяк и пиво, минимальное акцизное налоговое обязательство и специфические ставки на табачные изделия, введен утилизационный сбор на автомобили, акцизный сбор на табак стал собираться в авансовом режиме.

Важной мерой по повышению финансового потенциала можно считать введенный по инициативе автора налог на операции по отчуждению ценных бумаг и на операции с деривативами, используемыми для «оптимизации» налогов. При обосновании своего предложения автор исходил из того, что жизнеспособность «оптимизирующих» налоги компаний зависит от соотношения экономической целесообразности и уголовной ответственности за деятельность по «оптимизации» налогов. Следовательно, повышение налоговой нагрузки на такие посреднические компании приведет одновременно и к увеличению налоговых поступлений в бюджет от них и к сокращению рынка услуг по «оптимизации». О масштабе и значении этого явления говорит такой факт - в результате проведенных в 2013 г. мероприятий было раскрыто 2840 преступлений в сфере оказания финансовых услуг, сумма ущерба от которых составила 32,9 млн грн; из них обеспечено к возмещению свыше 30 млн грн. Однако эта целевая государственная программа по увеличению налоговых сборов, рассчитанная на пять лет, была свернута через два года; в результате структуры, обналичивающие средства, продолжили активно работать на рынке, а стоимость их услуг, по данным операторов этого рынка, выросла с 7-9\% в 2013 г. до 10-13\% в 2015 г. 
Рост доходов населения активно поглощался высоким спросом на иностранную валюту, а также привлекательными ставками по депозитам для граждан. Так, чистый спрос на валюту со стороны населения (т.е. превышение объемов покупки населением долларов, евро и другой инвалюты над объемами ее продажи в банки) в 2013 г. составил, по официальным данным НБУ, почти 2,9 млрд долл. Депозиты физических лиц за год выросли на $19,5 \%$, в том числе на $38 \%$ - в национальной валюте.

Слабый потребительский и инвестиционный спрос привел к снижению цен, что сигнализировало о негативных процессах в экономике и отсутствии стимулов для экономического роста. Так, индекс цен производителей промышленной продукции в 2013 г. составил 99,9\%, причем в металлургии падение отпускных цен составило $5 \%$, в добыче металлических руд - 3,4 , в добыче каменного угля $-7,5$, в производстве кокса и коксопродуктов - $11,5 \%$. Цены на потребительские товары упали за год, согласно данным Госстата, на $0,3 \%$. При этом продолжался умеренный рост цен и тарифов на услуги (гостиницы и рестораны - на 1,9\%, образование - на 3,4 , транспорт - на 2 , услуги отдыха и культуры - на 2,8 , услуги здравоохранения - на 2,3 , квартплата - на 2,6\%). Дефляция состоялась за счет таких товарных групп, как продукты питания (-2,4\%), одежда и обувь (-3\%).

Индекс потребительских настроений, регулярно рассчитываемый маркетинговой компанией GfK Ukraine с 2000 г. на основании опроса украинских домохозяйств, в 2012-2013 гг. стабилизировался в зоне 80-90 пунктов ${ }^{2}$. Однако начиная с декабря 2013 г. индикатор стал указывать на стремительное ухудшение потребительских настроений граждан в стране. В январе 2014 г. индекс потребительских настроений достиг отметки 72,5 пункта, а это означает, что уже лишь $36 \%$ людей наиболее активного возраста (15-59 лет) верят в улучшение экономической ситуации в стране в ближайшие 12 месяцев. Соответствующий индекс экономических ожиданий рухнул в начале 2014 г. до 71,3 пункта - антирекорд с марта 2011 г.

Роль экспорта как драйвера экономического роста постепенно снижалась. Если в 2011 г. физические объемы экспорта товаров и услуг выросли на 2,2\% при изменении дефлятора на $26,1 \%$, то в 2012 г. они уже упали на $7,7 \%$ при росте ценового фона на 9,8\%. В третьем квартале 2013 г. вывоз товаров и услуг сократился в физическом объеме на $7,8 \%$, однако дефлятор $(3,6 \%)$ оставался выше внутреннего. Соотношение экспорта товаров и услуг к объему ВВП страны сократилось до 45,9\% (в 2011 г. - 53,8\%).

Украина не подготовила свой ответ на политику импортозамещения, которую вела в последние годы Москва. Сокращение экспорта в Россию не

2. Это означает, что 40-45\% граждан считают, что их потребление будет расти; индекс имеет интервал от 0 до 200 пунктов. 
компенсировалось за счет других рынков (за исключением китайского). Выво3 товаров в Российскую Федерацию сократился за 2012-2013 гг. на 24\% с 19,82 млрд до 15,065 млрд долл. После событий конца 2013 г. крупнейшим внешнеторговым партнером Киева стал Европейский союз, куда было экспортировано 26,5\% товаров. Доля Российской Федерации сократилась до $23,8 \%$. В настоящее время экспорт в Россию практически полностью заморожен.

Разрушительный для экономики Украины характер приобрело противоречие между ЕС и Таможенным союзом. На этом фоне украинское правительство не смогло решить острое торговое противоречие выбора между зоной свободной торговли с Европейским союзом и Таможенным союзом. Полученная учеными из Национальной академии наук оценка инвестиций, желаемых в качестве компенсации потерь от европейского выбора, в размере 160 млрд долл. была воспринята основной частью общества как нежелание власти что-либо делать.

Продолжали действовать барьеры, ограничивающие способность предприятий увеличивать производство, в частности высокие цены на энергоносители, дефицит оборотных средств, чрезмерное налоговое давление, недостаточный спрос на продукцию и др.

В ноябре 2012 г. произошла девальвация акцента на реформы. Если в 2010-2011 гг. ключевой программный документ президента на пятилетку (Программа экономических реформ «Зажиточное общество, конкурентоспособная экономика, эффективное государство») выполнялся на $70-90 \%$, то в 2013 г. - менее чем на 40\%.

Можно сказать, что все эти факторы спровоцировали недовольство общества властью, что вылилось в события 2013-2014 гг. Как показали расчеты, проведенные в исследовании, период после переворота оказался катастрофическим с точки зрения социально-экономического развития. Отмечается не только усугубление существовавших проблем, но и появление новых, решение которых не может быть найдено в рамках действующей в Украине общественно-политической системы.

Главным макроэкономическим показателем, который характеризует уровень экономического развития страны, является ВВП (валовый внутренний продукт).

В 2014 г. ВВП на Украине на душу населения составил чуть больше 2 тыс. долл. США, что на 8,2\% меньше, чем показатели 2013 г. Нужно отметить, что в 2015 г. ВВП сократился уже на $11 \%$. Согласно данным МВФ, по показателю ВВП Украина находится на 105-м месте в мире. Для сравнения: в 2004 г. страна занимала 51-е место.

Практически вдвое вырос размер госдолга страны. В 2013 г. он составлял около $40 \%$, а в 2015 г. его размер уже превысил $70 \%$ ВВП. 
Промышленное производство Украины продолжает находиться в тяжелом кризисе. В 2014 г. оно уменьшилось на 10,7\%, а в 2015 г. уже на 16,6\%.

В результате действий украинских властей, направленных на дезинтеграцию отношений со странами Евразийского экономического союза (прежде всего с Россией), в стране в разы сократился сбыт промышленной продукции, что и повлекло за собой мощный кризис в сфере производства.

Уровень инфляции на Украине в 2014 г. составил 15,7\%, в $2015-43,3 \%$. Нужно отметить, что одним из основных факторов роста инфляции явилось существенное ослабление национальной валюты - гривны. В период обвала курса в начале 2015 г. до 40 грн за доллар цены на товары были пересмотрены именно исходя из этих показателей.

В 2015 г. курс гривны к доллару был на отметке в 23,83, в то время как в 2013 и 2014 гг. этот показатель составлял 7,94 и 15,74 грн соответственно. Необходимо отметить, что после неконституционной смены власти национальная валюта обесценилась примерно на $300 \%$.

Объем розничных продаж (в сопоставимых ценах) за январь-август 2015 г. сократился на $23,1 \%$ в сравнении с аналогичным периодом 2014 г. То есть за год темп сокращения уровня потребления населения Украины вырос почти в 6 раз.

Средняя реальная зарплата с начала 2015 г. сократилась на $26 \%$, а пенсия на $40 \%$. Бо́льшая часть населения страны выведена за черту бедности. По оценкам независимых экспертов, сейчас не менее $2 / 3$ населения Украины находится за чертой бедности, и темпы роста обнищания продолжают нарастать. Нельзя не отметить и резкое повышение тарифов на услуги ЖКХ, размер которых составляет бо́льшую часть доходов некоторых украинцев.

Таким образом, можно выделить три периода: 2007-2009 гг. - кризисный период с малоэффективной антикризисной политикой государства, 20102013 гг. - период поэтапного восстановления устойчивости (стабилизация производственного, финансового и внешнеэкономического потенциалов), 2014-2015 гг. - период рецидивного кризиса с ухудшением практически всех потенциалов.

С учетом продолжавшихся в 2016 г. негативных тенденций социальноэкономического развития Украины можно сделать вывод, что устойчивость развития страны находится на крайне низком уровне и продолжает снижаться (за исключением экологического потенциала). Это спровоцировано реализуемыми властью неэффективными мерами, направленными не на развитие экономики (прежде всего на формирование производственного потенциала), а на поиск средств для покрытия текущих расходов, значительная часть которых является неэффективными (что признается партнерами Украины из МВФ и Евросоюза). 


\section{РОССИЯ И МИР В ХХІ ВЕКЕ}

\section{Литература}

1. Анищенко А.В. Противодействие негативному влиянию долларизации национальной экономики на финансовую безопасность страны: диссертация ...кандидата экономических наук: 08.00.05 / Анищенко Александр Владимирович; [Место защиты: Рос. акад. нар. хоз-ва и гос. службы при Президенте РФ]. - Москва, 2013. - 178 с.

2. Fisher D. The World's Worst Economies // Forbes. Jul 5, 2011.

3. Paying Taxes 2014: The global picture. A comparison of tax systems in 189 economies worldwide. The World Bank/IFC. PwC. 